\title{
The impact of blood shear rate on arterial thrombus formation
}

The shear rate and corresponding shear stress have impacts on arterial thrombus formation. In particular, the effects of increasing concentration of platelets at the vessel wall and activation of platelets at this site increase the growth and stability of the thrombi which may result in a fatal narrowing of the arterial lumen. The efficacy of many antithrombotic agents is shear dependent as well. It is apparent that there is a need for a point-of-care device to rapidly monitor the risk for arterial thrombosis and to optimize antithrombotic therapy in vitro. The present review focuses on the essential role of shear rate on arterial thrombus formation in native human blood drawn directly from an antecubital vein.

Arterial thrombosis formation is to a large extent determined by the physical parameters of arterial blood flow, that is, shear rate and shear stress. In addition, the efficacy of many antithrombotic agents is dependent upon the shear. Consequently, there is a medical need for a rapid global assay to assess prothrombotic risk and antithrombotic treatment that is performed under arterial blood flow conditions, using native blood, which has not been in vitro anticoagulated.

Keywords: arterial stenosis • platelet activation • platelet adhesion • platelet aggregation

- shear rate • shear stress

\section{Identification of physical parameters of blood flow, shear rate \& shear stress}

The physical blood flow parameters, shear rate and shear stress were identified in the early 1970's and subsequently investigated for their potential impact on arterial thrombus formation [1-5]. Fully developed laminar blood flow in circular tubes, parallel-plate chambers or vessels can be characterized with a parabolic flow velocity profile, with velocity being maximal in the central part of the vessel and gradually diminishing as blood approaches the vessel wall (Figure 1). Correspondingly, the shear rate at the wall (termed the wall shear rate) is maximal where the flow gradient is greatest and the flow velocity is zero. For normal vascular flow, narrowing of the arterial diameter (stenosis) while maintaining blood flow rate constantly increases the wall shear rates and shear stresses that depend on the extent of reduction of the vessel lumen (in a manner that is inversely proportional to the cube of the vessel diameter, $1 / \mathrm{d} 3)$. This effect is demonstrated physiologically by the highest physiological shear rates and shear stresses being present in the smallest vessels. The strong dependence on wall shear rate and stresses on diameter, results in values of wall shear rate and shear stress in the presence of severe atherosclerotic arteries and at the surface of atherosclerotic plaques, become pathological and increase by one or two orders of magnitude over normal arterial shear conditions (Figure 2). The lowest values of wall shear rates and shear stresses are generally present in the larger vessels of the venous circulation.

The shear rate is defined as the rate of increase of blood flow velocity of adjacent
Kjell S Sakariassen ${ }^{*, 1}$, Lars Orning ${ }^{2}$

\& Vincent T Turitto ${ }^{3}$

${ }^{1}$ KellSa s.a.s., Str. Campo e Zampo 12,

I-13900 Biella, BI, Italy

${ }^{2}$ Alere Technologies AS, POB 6863

Rodelokka, N-0504 Oslo, Norway

${ }^{3}$ Illinois Institute of Technology,

3440 S. Dearborn Street, Chicago,

IL 60616, USA

*Author for correspondence:

kjell.sakariassen@kellsa.com 


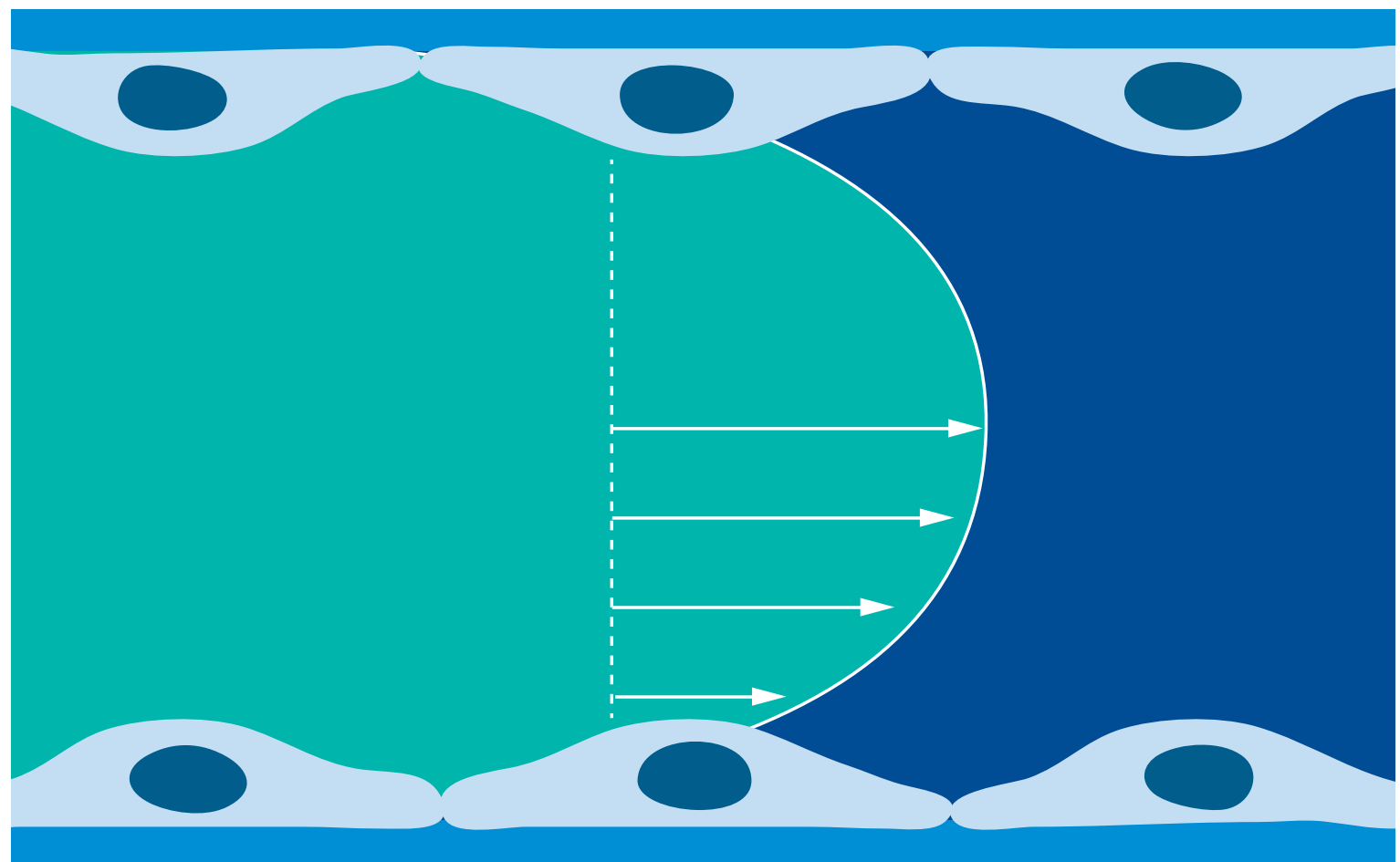

Figure 1. Artery parabolic blood flow velocity profile. Velocity is maximal in the central part of the vessel and gradually diminishes as blood approaches the vessel wall.

streaming layers (the slope of the velocity profile). The maximum value of the shear rate is located at the vessel wall and can be calculated as follows:

$$
\begin{aligned}
& \text { Wall shear rate }(\sec )^{1}: Y_{W}=4 Q / \pi r^{3} \\
& Q=\text { volumetric blood flow rate } \\
& r=\text { vessel wall radius }
\end{aligned}
$$

The shear stress which is defined as the force per unit area on the vessel wall can be calculated as follows:

$$
\begin{aligned}
& \text { Wall sheer stress }\left(\text { dynes } / \mathrm{cm}^{2}\right): \tau_{\mathrm{w}}=Y_{\mathrm{W}} \mu \\
& Y_{\mathrm{W}}=\text { wall shear rate } \\
& \mu=\text { blood viscosity }
\end{aligned}
$$

The gradient in the blood flow speed (slope of the velocity profile) in the laminar layers is highest at the vessel wall (Figure 1). This shear rate is termed wall shear rate. Under normal physiological flow conditions, the wall shear rate increases from about $10 \mathrm{~s}^{-1}$ in veins to about $2000 \mathrm{~s}^{-1}$ in the smallest arteries, whereas maximal wall shear rates up to $40,000 \mathrm{~s}^{-1}$ have been described for severe atherosclerotic arteries (Figure 2) [6,7]. The corresponding wall shear stresses are typically $0.35-70$ dynes $/ \mathrm{cm}^{2}$ in the normal vasculature to above 1500 dynes $/ \mathrm{cm}^{2}$ in diseased vessels depending on the degree of stenosis, as follows from the above equation with the blood flow vis- cosity assumed to be 0.035 centipoise ( $\mathrm{g} / \mathrm{cm}-\mathrm{s})$. It should be noted that such calculations are order of magnitude estimates for the specific shear conditions, especially in the sclerotic vessels where conditions are complex and computational methods have to be used to determine the actual distribution of shear conditions. For extensive stenosed conditions, the blood flow immediately distal to a severe atherosclerotic lesion may be significantly disturbed and possibly turbulent, promoting the formation of a fibrin-rich thrombus (Figure 3) [8].

Increasing shear rate results in an increase of erythrocytes in the central blood flow layers, which promotes a corresponding increase of platelets close to the vessel wall (Figure 4) [9]. In addition, erythrocytes, which constitute $40 \%$ of the blood volume are deforming and rotating. The complex interactions of these cells and their tendency to migrate away from the vessel wall due in part to lift forces induced by flow gradients promotes platelets to be transported toward the vessel wall, and results in an increase of the platelet count near the vessel wall [9-11]. This high concentration of platelets promoted in part by high wall shear rate and corresponding high wall shear stress contribute significantly to the rate and extent of arterial thrombus formation.

\section{Device \& method to study shear rate dependent arterial thrombus formation}

Shear rate dependent arterial thrombus formation was studied in a parallel-plate blood perfusion cham- 


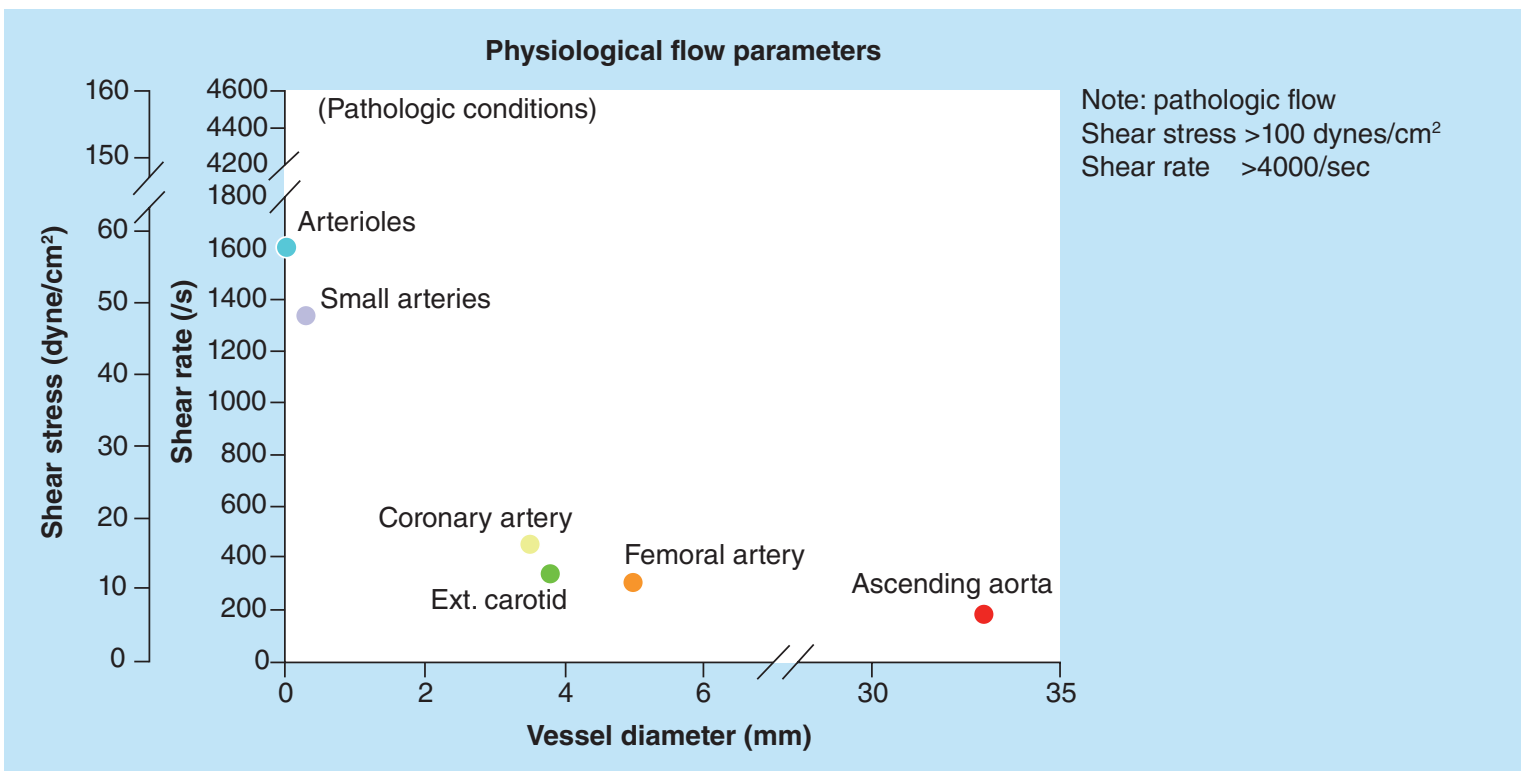

Figure 2. Vessel wall shear rates and corresponding shear stresses under normal physiological and pathological (stenosis) conditions.

ber device that draws human blood directly from an antecubital vein (Figure 5) [12,13]. The wall shear rates were experimentally determined and both wall shear rates and shear stresses can be theoretically calculated as well (Figure 6) [14]. Neither platelets nor coagulation are activated in the native blood drawn from the antecubital vein into the perfusion chamber. A broad range of prothrombotic surfaces can be employed in the perfusion chamber, for example, human type III collagen fibrils, human tissue factor plus phospholipids and human stimulated endothelial cells expressing tissue factors [15-18].

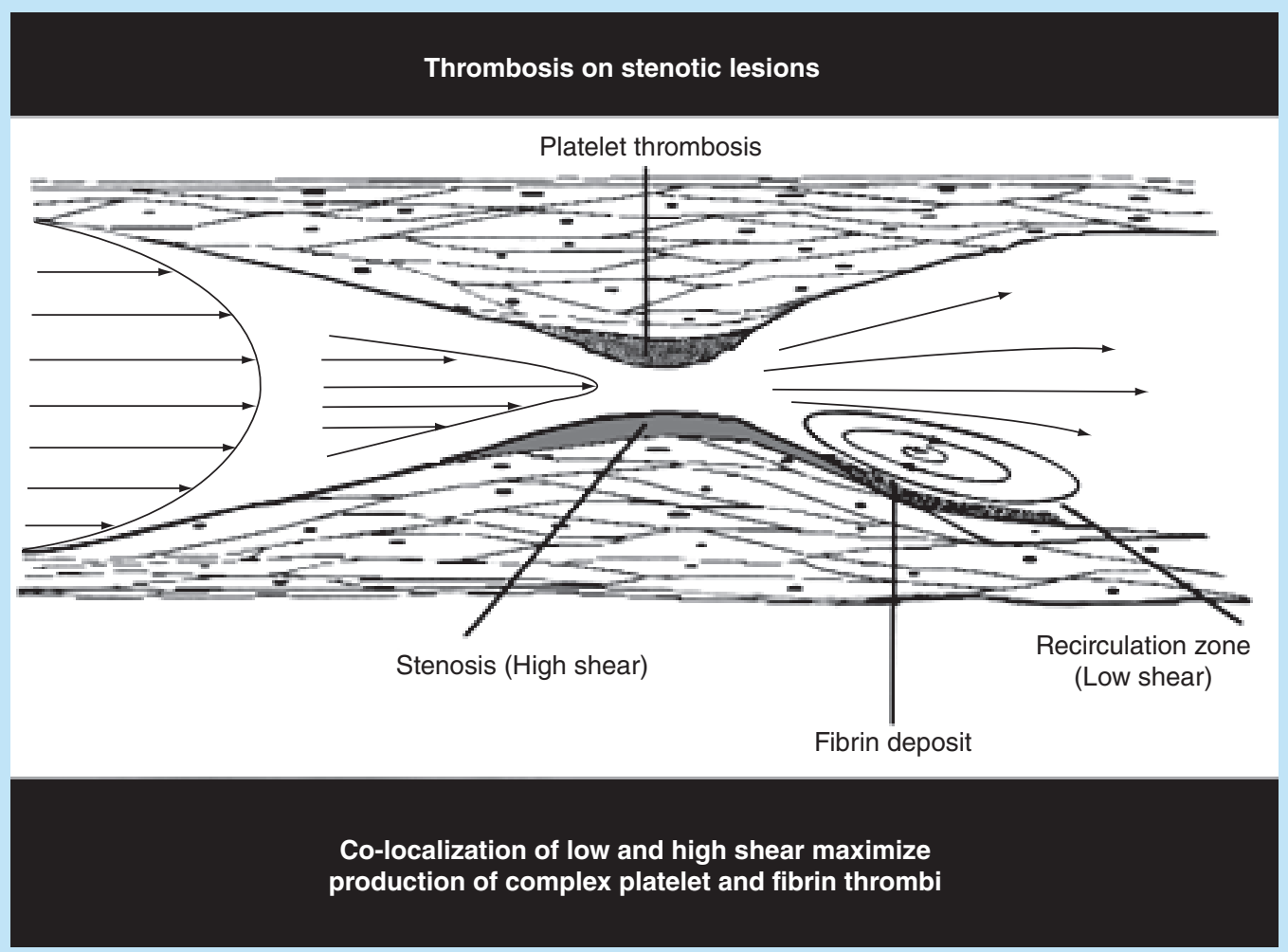

Figure 3. Blood flow properties and thrombus formation at an atherosclerotic/stenotic lesion. 


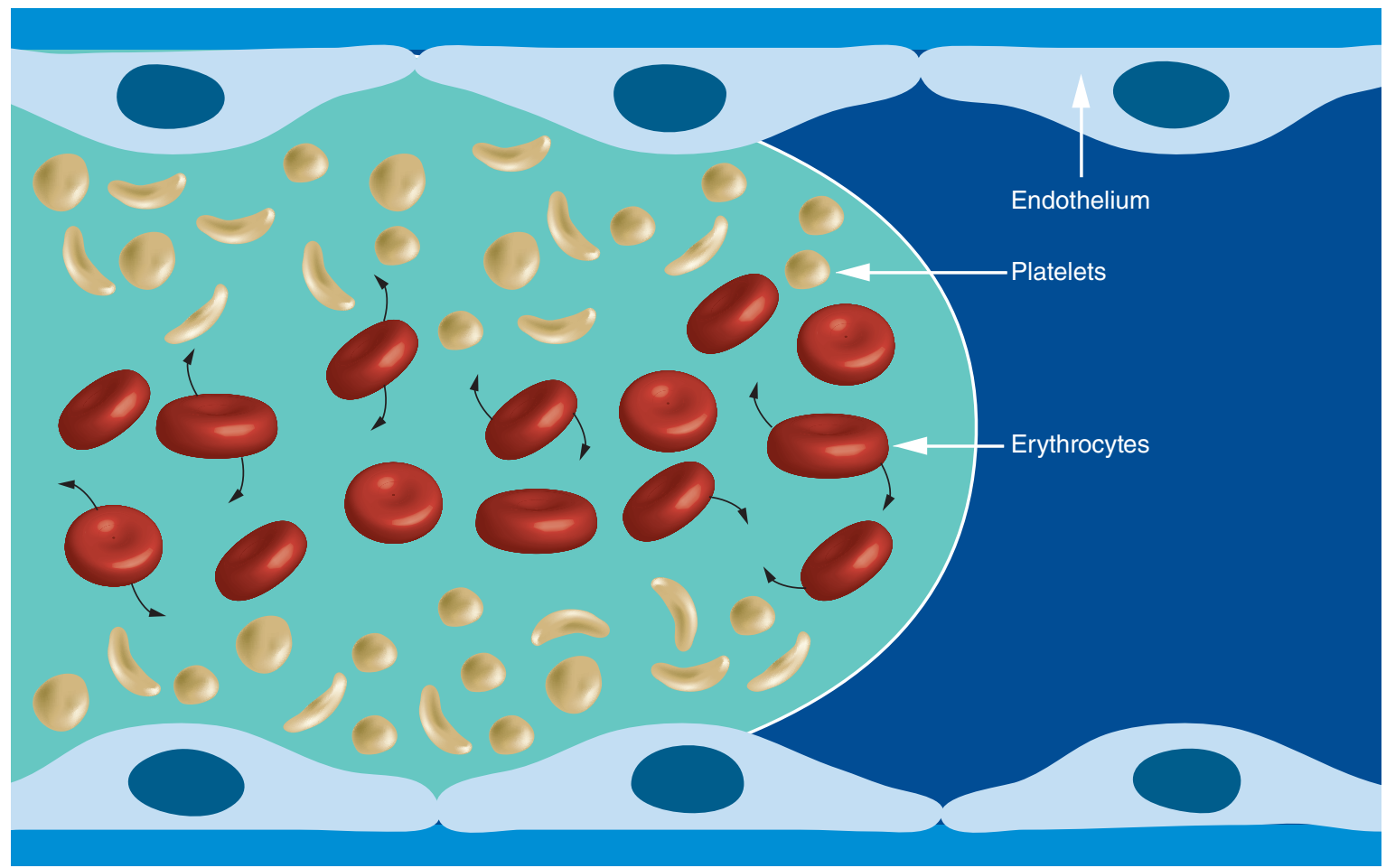

Figure 4. Distribution of platelets and erythrocytes in arterial flowing laminar blood. The rotating and deforming erythrocytes increase the concentration of platelets at the vessel wall.

Thrombus formation is assayed following 3-5 min of perfusion by computer-assisted light microscopy at $1000 \times$ magnification of 1 um thick epon embedded sections. The thrombotic deposits are classified as platelet adhesion (\% of surface covered by platelets), thrombus volume $(\mu \mathrm{m} 3 / \mu \mathrm{m} 2$ surface) and fibrin deposition (\% of surface covered by fibrin) [20]. In addition, platelet deposition is further assayed by determining the levels of P-selectin or $\beta$-TG as number of platelets $/ \mathrm{cm}^{2}$ and fibrin deposition is assayed by $\mathrm{d}$-dimer as $\mu \mathrm{g}$ fibrin $/ \mathrm{cm}^{2}$ following plasmin digestion of the thrombotic deposits [17,21-22]. The blood flow rate employed typically is $10 \mathrm{ml} / \mathrm{min}$ with the corresponding wall shear rates varying from 100 to $32.000 \mathrm{~s}^{-1}$ depending on the dimensions of the perfusion chamber blood flow channels and on the absence or presence of a stenosis in the flow channels (Table 1) $[14,22,23]$.

\section{Impact of shear rate on arterial thrombus formation}

The shear rate has a profound effect on the interactions of the platelets with the surface in the process of arterial thrombus formation. Platelet deposition is increased in parallel with the increasing shear rate [15,22-24]. The increase in shear rate both activates platelets and promotes their transport to and on and around the growing thrombus, resulting in both increased platelet adhesion and cohesion [15,24]. The combined increase of the near wall platelet numbers and platelet activation by high shear rates and shear stresses, respectively increases the thrombus growth in parallel $[23,25]$. Typically, these arterial thrombi are rich in platelets and have significantly less fibrin than venous thrombi, and are characteristic of the white thrombus found in arteries. Key platelet receptors for adhesion and cohesion are GPIb and GPIIb-IIIa [26,27]. The coagulation protein thrombin is a strong activator of platelets and their cohesion, and is also a key protein in the formation of fibrin which stabilizes the growth of mural thrombi and physically resists the flow forces due to shear stress and the blood pressure [13]. The effect of the shear rate on arterial thrombus formation with regard to various platelet receptors and coagulation factors was studied with the parallel-plate blood perfusion chamber device with human type III collagen fibrils as prothrombotic surface (Figure 5) [12-15]. The following hereditary bleeding disorders were studied: severe deficiency of vWF, known as von Willebrand disease (vWD subtype III), the vWD subtypes vWD I, vWD IIa, vWD IIb and vWD 2M, deficiency of the platelet receptors GPIa, GPIb and GPIIb-IIIa, and polymorphisms of GPIa, GPIb and GPIIb-IIIa. It is apparent that the deposition of platelets on surfaces exposed to many deficiencies/abnormalities of vWF and platelet receptors is highly shear rate dependent, both with regard to platelet adhesion and cohesion. 
Increasing shear rate decreased the platelet cohesion, resulting in a gradual decrease in thrombus formation. This was the case for the vWF deficiency and the vWD subtypes investigated [28,29]. Polymorphism GPIa $(C 807 T)$ increased platelet cohesion at high arterial shear rate [30]. Polymorphism of GPIb $(V N T R)$ had no effect on thrombus formation, whereas the GPIb (Kozak type) increased platelet cohesion at low arterial shear rate [30]. GPIIb-IIIa deficiency reduced both platelet cohesion and fibrin deposition [12].

The shear rate dependence of thrombus formation associated with deficiencies of the coagulation factors FVII and FVIII was studied on human type III collagen fibrils. Fibrin deposition was decreased at all shear rates tested [28,31]. Reduced platelet cohesion was present at low shear rates with low plasma levels of FVIII, whereas reduced platelet cohesion was observed at high shear rate with low plasma levels of FVII.

It is apparent that the deficiency and various $\mathrm{vWD}$ subtypes and the deficiency and polymorphism of the studied platelet receptors and coagulation proteins affect the mechanisms of thrombus formation in a somewhat contrasting manner which appears largely dependent on the local wall shear rate. The impact of the tested platelet receptors appear best demonstrated at high arterial shear rate, whereas the low level plasma coagulation factors tested appear at both high and low arterial shear rates. It should be emphasized that the chemical nature of the thrombogenic surface, whether procoagulant or not, may affect the impact of low plasma levels of FVII and FVIII on thrombus formation.
It should also be mentioned that nonlaminar turbulent-like blood flow as present immediately downstream to a severe atherosclerotic lesion promotes in particular coagulation and deposition of fibrin, presumably due to the low shear conditions there and the preexposure to the upstream reactive stenosis (Figure 3). The propagation of this activation of the coagulation system result in the creation of a fibrinrich tail of the thrombus [32]. The impact of such blood flow conditions on the studied platelet receptors and low level of plasma coagulation factors has not yet been studied.

\section{Impact of shear rate on antiplatelet agents on arterial thrombus formation}

A broad spectrum of antiplatelet agents at optimal clinical doses have been investigated and compared at various well-controlled wall shear rates by using the parallel-plate blood perfusion device (Figure 5) [12-14]. Purified human type 3 collagen fibrils were generally employed as the reactive surface, although some studies were performed with a human tissue factor/phospholipid surface and a procoagulant cellular matrix of human endothelial cells [15-18].

The thromboxane inhibitor, aspirin, inhibited human collagen induced thrombus formation at arterial shear rates, but lost its antithrombotic efficacy at an arterial wall shear rate of $10,500 \mathrm{~s}^{-1}$. The loss of antiplatelet efficacy of aspirin at high arterial shear rates has also been demonstrated in patients with severe atherosclerotic lesions [33]. The ADP receptor antagonists ticlopidine and clopidogrel, and the thromboxane receptor antagonist linotroban all

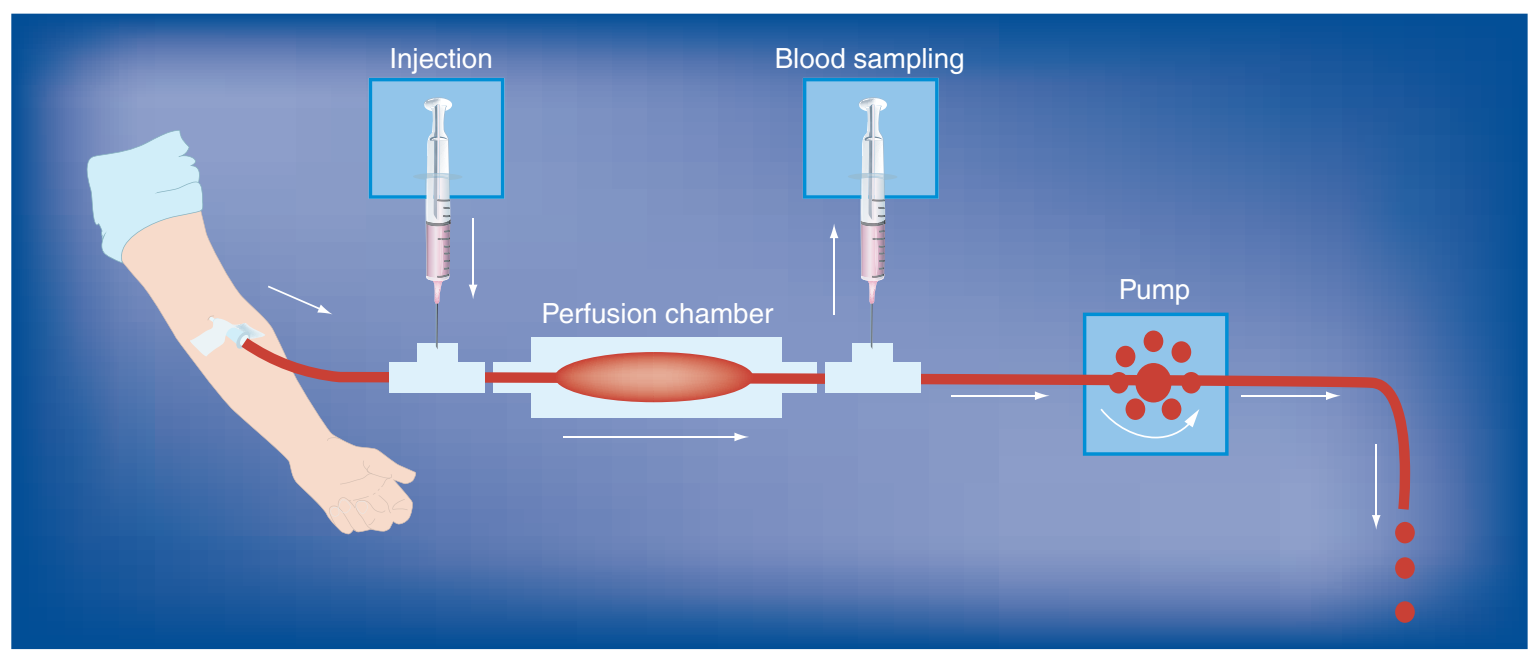

Figure 5. Human ex vivo parallel-plate blood perfusion device. Blood is drawn from an antecubital vein by the pump. Ex vivo studies of therapeutic agents not requiring in vivo metabolism can be injected upstream to the perfusion chamber with the reactive surface. Blood sampling for biomarker analysis can be collected downstream to the perfusion chamber.

Reproduced with permission from [19] @ Future Medicine (2007). 


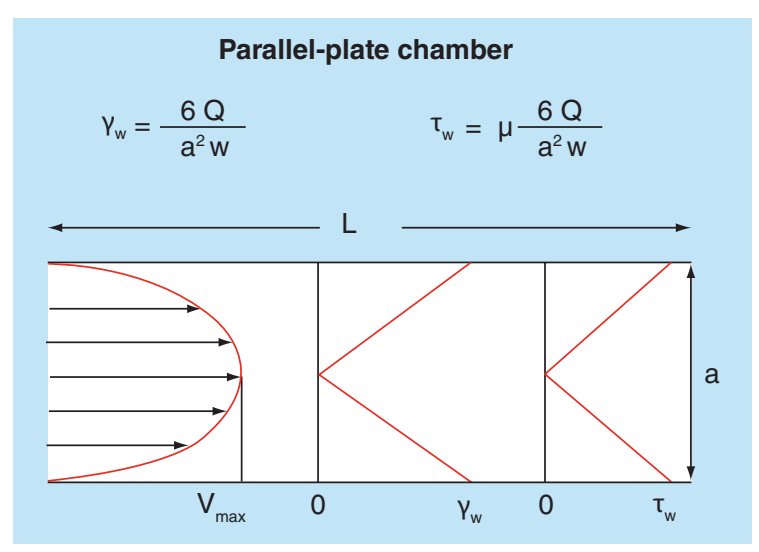

Figure 6. Typical blood flow velocity profile in the parallel-plate blood perfusion chamber. The shear rate and shear stress profiles would basically be related to the slope of the velocity profile - zero at center and maximal at the wall where the velocity is zero. Formulas for calculation of wall shear rate $(Y)$ and shear stress $(\mathrm{u})$ are indicated above the figure.

inhibited human collagen induced thrombus formation at all arterial wall shear rates studied [34-36]. The GPIIb-IIIa inhibitors RGDS and Ro 44-9883 inhibited human collagen and human cellular matrix induced arterial thrombus formation as well $[17,37]$. Clopidogrel at the optimal clinical dose appeared as the most efficient inhibitor of arterial thrombus formation.

Combination therapies of aspirin and ticlopidine, aspirin and clopidogrel and aspirin and dipyridamole enhanced the antithrombotic efficacy of each of the antiplatelet agents $[34,38,39]$. Dipyridamole is an antiplatelet agent which increases the uptake of adenosine resulting in high levels of cAMP which have been demonstrated to inhibit platelet function [40]. The most potent antithrombotic efficacy was observed with the combinations of aspirin and ticlopidine and aspirin and clopidogrel. In this regard it is interesting to note that a combination of aspirin and clopidogrel is currently used therapeutically to avoid cardiovascular events in acute coronary syndromes and in vascular stent induced thrombosis [41]. Combination of aspirin and dipyridamole is used as a therapeutic approach to avoid secondary stroke events [42].

\section{Impact of shear rate on anticoagulants on arterial thrombus formation}

A number of anticoagulants, including low molecular weight heparin, fraxiparine, the vitamin $\mathrm{K}$ antagonists fluinidone and marevan, the thrombin inhibitor PEG-hirudin and inhibitors of FVIIa, tissue factor, tissue factor/FVIIa, thrombin, FXa and FIXa were also investigated with the parallel-plate blood perfusion device in a manner similar to that of the antiplatelet agents (Figure 5) [12-14]. The procoagulant surfaces used in the blood perfusion device were tissue factor/phospholipids, subendothelium containing tissue factor and human type III collagen fibrils [15-17]. In general, it was found that the anticoagulants were most efficient in inhibiting platelet cohesion and fibrin deposition on the procoagulant surfaces and much less on the collagen surface at the various arterial wall shear rates tested [13,17,43-49]. The corresponding fibrin deposition was reduced to a similar extent on the various surfaces.

Other physiological anticoagulants, including tissue factor pathway inhibitor, annexin V, ATRA were tested as well, and found to significantly inhibit fibrin deposition at shear rates below $650 \mathrm{~s}^{-1}$ [50-52].

A combination therapy of fluinidone and aspirin was tested at high arterial shear rate $\left(2.600 \mathrm{~s}^{-1}\right)$ on both human type III collagen fibrils and tissue factor/phospholipid surfaces. Significant inhibition of platelet cohesion and fibrin deposition was observed on both surfaces, although the inhibition was most pronounced on the procoagulant surface [45].

A more detailed analysis of the data obtained with the parallel-plate blood perfusion device with regard to platelet and coagulation disorders and to the effects of antithrombotics and prohemostatic compounds were previously reported together with data obtained by other blood perfusion devices $[4,19,53]$.

\section{Table 1. Selected ex vivo perfusion chamber models of human thrombosis}

\begin{tabular}{|c|c|c|}
\hline Chamber type & Wall shear rate $\left(\mathrm{s}^{-1}\right)$ at $10 \mathrm{ml} / \mathrm{min}$ & Corresponding vessel condition \\
\hline Parallel & 100 & Venous \\
\hline Parallel & 650 & Average-sized arteries \\
\hline Parallel & 2600 & Diffuse atherosclerosis \\
\hline Stenosis $^{\dagger}$ & 2600 & Moderate arterial stenosis \\
\hline Stenosis $^{\dagger}$ & 10,500 & Severe arterial stenosis \\
\hline Stenosis ${ }^{\dagger}$ & 32,000 & Very severe arterial stenosis \\
\hline
\end{tabular}




\section{Conclusions and future perspective}

Improved understanding of the factors that influence thrombosis, the conditions under which antithrombotic therapies need to be tested and the eventual development of such therapies that block thrombotic events without affecting hemostasis are sorely needed. Such developments will lead to better assessment of thrombotic risk and its treatment and improved treatment of patient care. The increased interest in chamber-based assays to measure thrombus formation has prompted international recommendations for a standardization of devices, protocols and measurement parameters of flow chambers [54-56].

A point-of-care device to rapidly monitor the risk for arterial thrombosis and to optimize antithrombotic therapy is highly needed. Such a device should assess the thrombotic risk in native blood at various arterial shear rates and avoid the artifacts of in vitro anticoagulation.

\section{Author contributions}

All authors contributed as writers of the text and prepared the various figures and the table.

\section{Financial \& competing interests disclosure}

One of the authors, KS Sakariassen of KellSa s.a.s., consults/ advices academic and biopharma R\&D within the areas of hemostasis, thrombosis and atherosclerosis. The authors have no other relevant affiliations or financial involvement with any organization or entity with a financial interest in or financial conflict with the subject matter or materials discussed in the manuscript apart from those disclosed.

No writing assistance was utilized in the production of this manuscript.

\section{Open access}

This work is licensed under the Creative Commons Attribution 4.0 License. To view a copy of this license, visit http:// www.creativecommons.org/licenses/by/4.0/

\section{Executive summary}

- It is fair to conclude that the impact of the wall shear rate on arterial thrombosis has gained much attention and has resulted in improved understanding of the pathogenesis of thrombotic disorders and its treatment in general.

- The increased interest in chamber-based assays to measure thrombus formation has prompted international recommendations for a standardization of devices, protocols and measurement parameters of flow chambers.

- Much remains to be explored, particularly regarding improvements needed to determine optimal efficiencies in individual subjects at the level of personalized medicine. This goal may be reached by the development of a shear rate dependent point-of-care global prothrombotic/hemostasis assay making use of blood samples not anticoagulated in vitro.

\section{References}

1 Baumgartner HR. The role of blood flow in platelet adhesion, fibrin deposition and formation of mural thrombi. Microvasc. Res. 5, 167-179 (1973).

2 Weiss HJ, Turitto VT, Baumgartner HR. Effect of shear rate on platelet interaction with subendothelium in citrated and native blood. 1. Shear-dependant decrease of adhesion in von Willebrand's ddisease and the Bernard-Soulier syndrome. J. Lab. Clin. Med. 92, 750-764 (1978).

3 Baumgartner HR, Sakariassen KS. Factors controlling thrombus formation on arterial lesions. Ann. NY Acad. Sci. 454, 162-177 (1985).

4 Sakariassen KS, Hanson SR, Cadroy Y. Methods and models to evaluate shear-dependent and surface reactivity-dependent antithrombotic efficacy. Thromb. Res. 104, 149-174 (2001).

5 Sakariassen KS, Turitto VT, Baumgartner. Recollections of the development of flow devices for studying mechanisms of hemostasis and thrombosis in flowing whole blood.

J. Thromb. Haemost. 2, 1681-1690 (2004).

6 Roux SP, Sakariassen KS, Turitto VT et al. Effect of aspirin and epinephrine on experimentally-induced thrombogenesis in dogs: a parallelism between in vivo and ex vivo thrombosis models. Arterioscler. Thromb. 11, 1182-1191 (1991).
7 Strony J, Beaudin A, Brands D et al. Analysis of shear stress and hemodynamic factors in a model of artery stenosis and thrombosis. Am. J. Physiol. 265, H1787-H1796 (1993).

8 Hutchison KJ, Karpinski E. In vivo demonstration of flow recirculation and turbulence downstream of graded stenoses in canine arteries. J. Biomech. 18(4), 285-296 (1985).

9 Aarts PA, van den Broek SA, Prins GW et al. Blood platelets are concentrated near the wall and red blood cells in the center in flowing blood. Arteriosclerosis 8(6), 819-824 (1988).

10 Turitto VT. Blood viscosity, mass transport, and thrombogenesis. In: Progress In Hemostasis And Thrombosis. Spaet TM (Ed.). Grune \& Stratton, NY, USA 5, 139-174 (1981).

11 Goldsmith HL, Turitto VT. Rheological aspects of thrombosis and hemostasis: basic principles and applications. Thromb. Haemost. 55, 415-435 (1986).

12 Sakariassen KS, Fressinaud E, Girma JP et al. Role of platelet membrane glycoproteins and von Willebrand factor in adhesion of platelets to subendothelium and collagen. Ann. NY Acad. Sci. 516, 52-65 (1987).

13 Orvim U, Barstad RM, Vlasuk GP et al. Effect of selective factor $\mathrm{Xa}$ inhibition on arterial thrombus formation triggered by tissue factor/factor VIIa or collagen in an ex vivo model 
of human shear dependent thrombus formation. Arterioscler. Thromb. Vasc. Biol. 15, 2188-2194 (1995).

14 Sakariassen KS, Aarts PAMM, de Groot PG et al. A perfusion chamber developed to investigate platelet interaction in flowing blood with human vessel wall cells, their extracellular matrix, and purified components. J. Lab. Clin. Med. 102, 522-535 (1983).

15 Sakariassen KS, Joss R, Muggli R et al. Collagen type III induced ex vivo thrombogenesis in humans. Role of platelets and leukocytes in deposition of fibrin. Arteriosclerosis 10(2), 276-284 (1990).

16 Orvim U, Roald HE, Stephens RW et al. Tissue factorinduced coagulation triggers platelet thrombus formation as efficiently as fibrillar collagen at arterial blood flow conditions. Arterioscler. Thromb. 14(12), 1976-1983 (1994).

17 Aznar-Salatti J, Anton P, Nemerson Y et al. Modulation of procoagulant activity of extracellular endothlial matrix by anti-tissue factor and the synthetic peptide arg-gly-asp-val. Experiments with flowing non-antigoaulated blood. Blood Coag. Fibrinol. 4(6), 881-890 (1993).

18 Diquelou A, Dupouy D, Gaspin D et al. Relationship between endothelial tissue factor and thrombogenesis under blood flow conditions. Thromb. Haemost. 74(2), 778-783 (1995).

19 Sakariassen KS. Thrombus formation on apex of arterial stenoses: the need for a fluid high shear diagnosis device. Future Cardiol. 3(2), 193-201 (2007).

20 Sakariassen KS, Kuhn H, Muggli R et al. Growth and stability of thrombi in flowing citrated blood: assessment of plateletsurface interactions with computer-assisted morphometry. Thromb. Haemost. 60 (33), 392-398 (1988).

21 Orvim U, Barstad M, Stormorken H et al. Immunological quantification of fibrin deposition in thrombi formed in flowing native blood. Brit. J. Haematol. 95, 389-398 (1996).

22 Bossavy JP, Sakariassen KS, Barret A et al. A new method for quantifying platelet deposition in flowing native blood in an ex vivo model of human thrombogenesis. Thromb Haemost. 79, 162-168 (1998).

23 Barstad RM, Roald HE, Cui Y et al. A perfusion chamber developed to investigate thrombus formation and shear profiles in flowing native human blood at the apex of well-defined stenoses. Arterioscler. Thromb. 14(12), 1984-1991 (1994).

24 Baumgartner HR, Sakariassen KS. Factors controlling thrombus formation on arterial lesions. Ann. NY Acad. Sci. 454, 162-177 (1985).

25 Barstad RM, Kierulf P, Sakariassen KS. Collagen-induced thrombus formation at the apex of eccentric stenoses. A time-course study with non-anticoagulated blood. Thromb. Haemost. 75(5), 685-692 (1996).

26 Weiss HJ, Turitto VT, Baumgartner HR. Platelet adhesion and thrombus formation on subendothelium in platelets deficient in glycoproteins IIb-IIIa, Ib and storage granules. Blood 67, 322-330 (1986).

27 Weiss HJ, Turitto VT, Baumgartner HR. Role of shear rate and platelets in promoting fibrin formation on rabbit subendothelium. Studies utilizing patients with quantitative and qualitative platelet defects. J. Clin. Invest. 78, 1072-1082 (1986).
28 Fressinaud E, Sakariassen KS, Rothschild C et al. Sheardependent impairment of thrombus growth on collagen in non-anticoagulated blood from patients with von Willebrand disease and Hemophilia A. Blood 80, 988-994 (1992).

29 Barstad RM, Orvim U, Hamers MJAG et al. Reduced effect of aspirin on thrombus formation at high shear and disturbed laminar blood flow. Thromb. Haemost. 75, 827-832 (1996).

30 Cadroy Y, Sakariassen KS, Charlet JP et al. Role of 4 platelet membrane glycoprotein polymorphisms on experimental arterial thrombus formation in men. Blood 98 1097-1103 (2001).

31 Barstad RM, Stormorken H, Orning L et al. Reduced thrombus formation in native blood of homozygous factor VII deficient patients at high arterial wall shear rate. Blood 84, 3371-3377 (1994).

32 Sakariassen KS, Barstad RM. Mechanisms of thrombus formation at arterial plaques. Blood Coag. Fibrinol. 4, 615-625 (1993).

33 Veen G, Meyer A, Verheugt FW et al. Culprit lesion morphology and stenosis severity in the prediction of reocclusion after coronary thrombolysis: angiographic results of the APRICOT study. Antithrombotics in the prevention of reocclusion in coronary thrombolysis. J. Am. Coll. Cardiol. 22, 1755-1762 (1993).

34 Bossavy JP, Thalamas C, Sagnard L et al. A doubleblind randomized comparison of combined aspirin and ticlopidine therapy versus aspirin and ticlopidine alone on experimental arterial thrombogenesis in humans. Blood 92, 1518-1525 (1998).

35 Roald HE, Barstad RM, Kierulf P et al. Clopidogrel - a platelet inhibitor which inhibits thrombogenesis in human non-anticoagulated blood independently of the blood flow conditions. Thromb. Haemost. 71, 665-672 (1994).

36 Roald HE, Barstad RM, Engen A et al. HN-1150 - a novel thromboxane $\mathrm{A} 2$ receptor antagonist with antithrombotic activity in humans at arterial blood flow conditions. Thromb. Haemost. 71, 103-109 (1994).

37 Kirchhofer D, Tschopp TB, Steiner B et al. Role of collagen-adherent platelets in mediating fibrin formation in flowing whole blood. Blood 86, 3815-3822 (1995).

38 Cadroy Y, Bossavy JP, Thalamas C et al. Early potent antithrombotic effect with combined aspirin and a loading dose of clopidogrel on experimental arterial thrombogenesis in humans. Circulation 101, 2823-2828 (2000).

39 Cadroy Y, Thalamas C, Sakariassen KS et al. Superior efficacy of clopidogrel plus acetylsalicyclic acid compared with extended-release dipyridamole plus acetylsalicyclic acid in preventing arterial thrombosis in healthy volunteers. Thromb. Res. 116, 293-300 (2005).

40 Harker LA, Kadatz RA. Mechanism action of dipyridamole. Thromb. Res. 29(1), 39-46 (1983).

41 Terpening C. An appraisal of dual antiplatelet therapy with clopidogrel and aspirin for prevention of cardiovascular events. J. Am. Board Fam. Med. 22(1), 51-56 (2009).

42 Halkes PH, van Gijn J, Kapelle LJ, Koudstaal PJ, Algra A. Aspirin plus dipyridamole versus aspirin alone after 
ischaemia of arterial origin (ESPRIT): randomized controlled trial. Lancet 367, 1665-1673 (2006).

Diquelou A, Dupouy D, Cariou R et al. A comparative study of the anticoagulant and antithrombotic effects of unfractionated heparin and a low molecular weight heparin (Fraxiparine) in an experimental model of human venous thrombosis. Thromb. Haemost. 74, 1286-1292 (1995).

Kirchhofer D, Tschopp TB, Baumgartner HR. Active siteblocked factors VIIa and IXa differentially inhibit fibrin formation in a human ex vivo thrombosis model. Arterioscler. Thromb. Vasc. Biol. 15, 1098-1106 (1995).

45 Bossavy JP, Sakariassen KS, Thalamas C et al. Antithrombotic efficacy of the vitamin $\mathrm{K}$ antagonist fluinidone in a human ex vivo model of arterial thrombosis. Effect of anticoagulation level and combination therapy with aspirin. Arterioscler. Thromb. Vasc. Biol. 19, 2269-2275 (1999).

46 Bossavy JP, Sakariassen KS, Rubsamen K et al. Comparison of the antithrombotic effect of PEG-hirudin and heparin in a human model of arterial thrombosis. Arterioscler. Thromb. Vasc. Biol. 19, 1348-1353 (1999).

47 Kirchhofer D, Tschopp TB, Hadvary P et al. Endothelial cells stimulated with tumor necrosis factor-alpha express varying amounts of tissue factor resulting in inhomogenous fibrin deposition in a native blood flow system. J. Clin. Invest. 93, 2073-2083 (1994).

48 Orvim U, Barstad RM, Orning L et al. Antithrombotic efficacy of inactivated active site recombinant factor VIIa is shear dependent in human blood. Arterioscler. Thromb. Vasc. Biol. 17, 3049-3056 (1997).

Orning L, Fischer PM, Hu CK et al. A cyclic pentapeptide derived from the EGF-2 like domain of factor VII is an inhibitor of tissue factor dependent coagulation and thrombus formation. Thromb. Haemost. 87, 13-21 (2002).

50 Lindahl AK, Sandset PM, Thune-Wiger M et al. Tissue factor pathway inhibitor prevents fibrin deposition on procoagulant subendothelial matrix when exposed to flowing non-anticoagulated human blood. Blood Coag. Fibrinol. 5 , 755-760 (1994).

51 van Heerde WL, Sakariassen KS, Hemker HC et al. Annexin $\mathrm{V}$ inhibits the procoagulant activity of TNF-stimulated endothelial cells under flow conditions. Arterioscler. Thromb. 14, 824-830 (1994).

52 Barstad RM, Hamers MJAG, Stephens RW et al. Retinoic acid reduces induction of monocyte tissue factor and tissue factor/factor VIIa dependent thrombus formation. Blood 86, 212-218 (1995).

53 Sakariassen KS. Blood flow devices in medical research and clinical testing in humans: are we approaching personalized medicine? Future Cardiol. 3(1), 71-90 (2007).

54 Zwaginga JJ, Nash G, King MR et al. Flow-based assays for global assessment of hemostasis. Part 1: biorheological considerations. J. Thromb. Haemost. 4, 2486-2487 (2006).

55 Zwaginga JJ, Sakariassen KS, Nash G et al. Flow-based assays for global assessment of hemostasis. Part 2: current methods and considerations for the future. J. Thromb. Haemost. 4, 2716-2717 (2006).

56 Roest M, Reininger A, Zwaginga JJ et al. Flow chamberbased assays to measure thrombus formation in vitro: requirements for standardization. J. Thromb. Haemost. 9 , 2322-2324 (2011). 